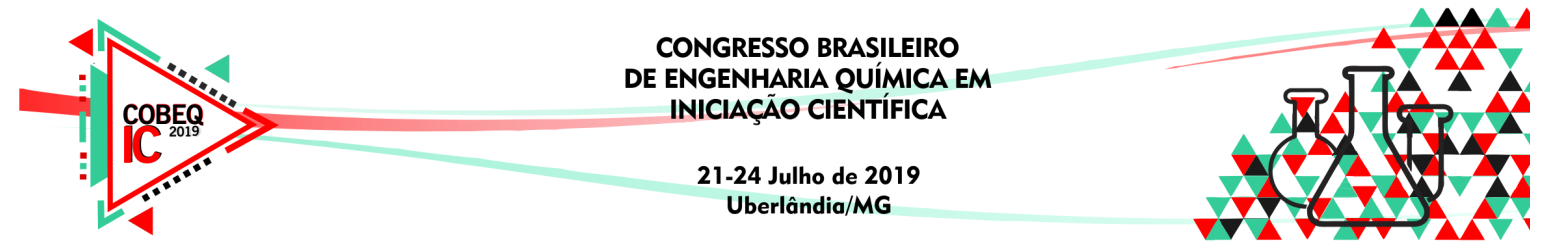

\title{
METALS RECOVERY FROM THE GOLD PRESSURE OXIDATION STAGE EFFLUENT USING SOLVENT EXTRACTION
}

V. R. MOREIRA ${ }^{1}$, Y. A. R. LEBRON ${ }^{1}$, A. F. S. FOUREAUX ${ }^{2}$, L. V. S. SANTOS ${ }^{1,2}$ e M. C. S. AMARAL ${ }^{2}$

${ }^{1}$ Pontifical Catholic University of Minas Gerais, Department of Chemical Engineering

${ }^{2}$ Federal University of Minas Gerais, Sanitary and Environmental Engineering Department E-mail para contato: victorrznde.eng@gmail.com

\begin{abstract}
The gold mining, accompanied with the production increase, generates a large effluent amount throughout its process, resulting in several environmental impacts if not correctly destined. In this context, the solvent extraction emerges as an alternative to recover value-added compounds present in this effluent. In this work, Cyanex 272 was employed, in different aqueous/organic $(\mathrm{A} / \mathrm{O})$ ratios, to recover metals from a pressure oxidation stage synthetic effluent. The metals concentration in the aqueous phase was determined by atomic absorption spectroscopy. Distribution coefficient and separation factors were calculated. The highest concentration in the organic phase was iron due to the higher driving force for the extraction. The highest average removal was for manganese $(40.8 \%)$. Furthermore, the highest selectivity was obtained for the $2 / 1 \mathrm{~A} / \mathrm{O}$ ratio, being the manganese the metal that presented greater selectivity against iron.
\end{abstract}

\section{INTRODUCTION}

The gold mining is associated to numerous technological and industrial segments. Its production increased by $12 \%$ between 2000 and 2013, accompanied by a 5.2-fold increase in its price per ton (World Gold Council, 2012). The growth observed, however, reflects on the amount of wastewater generated throughout its beneficiation process, which can result in several environmental impacts if not correctly disposed. The effluents present a varied composition, which depend on the mine region geochemical characteristics and the beneficiation process employed (Reis et al., 2018). Usually, toxic compounds such as heavy metals, metalloids and acids are commonly found in their composition. One of the techniques commonly used in their treatment is the neutralization process, that uses alkalinizing reagents such as calcium carbonate, calcium oxide, calcium hydroxide, magnesium hydroxide or sodium hydroxide (Amaral et al., 2018). Even though it is considered a simple treatment process, it presents the disadvantage of sludge generation, which hamper metals and acid recovery that present an added value.

The solvent extraction (SX) process emerges as an alternative to the conventional forms employed, being a consolidated technology of great industrial applicability. In addition to the benefit of recovering value-added compounds, the treatment used allows the operation with effluents that presents high metals and acid concentration. This technique involves contacting two immiscible liquids by agitation, one aqueous phase and the other organic phase. In this 


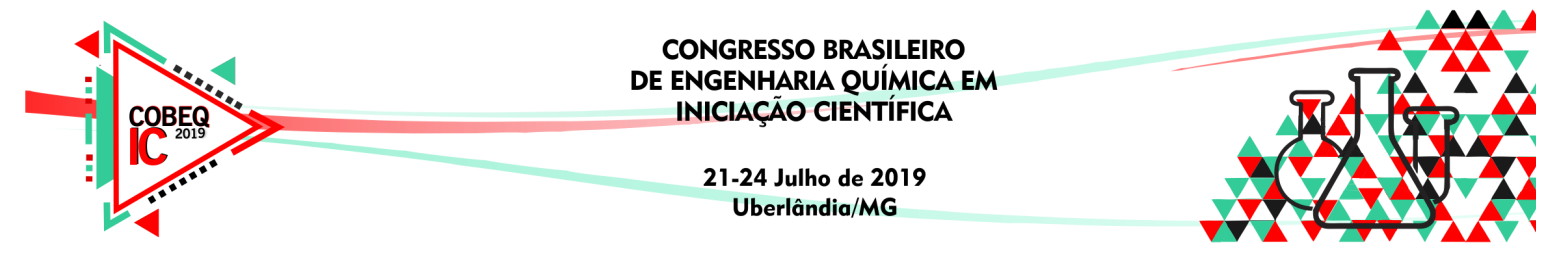

process, the metal present in the aqueous phase is transferred to the organic phase through the interaction of the extractant with the metal ion according to Equation 1, where $M^{n+}$ is the metal ion of interest and $R$ is the extractant molecule.

$$
M^{n+}+n R H \rightleftharpoons M R_{n}+n H^{+}
$$

Bis(2,4,4-trimethylpentyl) phosphinic acid or Cyanex 272, is an acidic type of an organophosphorus extractant. Cyanex 272 can effectively extract metals such as iron, zinc, copper, cobalt, cadmium and vanadium. Besides, it has been widely used in the rare earth industry (Banda et al., 2012). Thus, the SX process was evaluated in the remediation of a synthetic effluent similar to that generated in the gold-mining sector, evaluating the influence of different aqueous/organic $(\mathrm{A} / \mathrm{O})$ ratios on metal ions recovery.

\section{MATERIALS AND METHODS}

\subsection{Organic phase preparation}

A 60 vol.\% Cyanex 272 in n-hexane $\left(\right.$ Synth $\left.^{\circledR}\right)$ was prepared. During the solvent extraction experiments, no third phase formation was not observed which dispensed the use of modifiers for the organic phase preparation.

\subsection{Synthetic effluent preparation}

A synthetic effluent was prepared based on concentration levels similar to those reported on the literature (Amaral et al., 2018). All reagents used were of analytical grade and were dissolved in ultrapure water (MilliQ). After salts addition, the $\mathrm{pH}$ was adjusted using analytical grade sulfuric acid $\left(\mathrm{H}_{2} \mathrm{SO}_{4}\right)$. Physical and chemical properties of the synthetic effluent are presented in Table 1 .

Table 1 - Effluent physicochemical properties

\begin{tabular}{|c|c|c|c|c|}
\hline Metal & $\begin{array}{c}\text { Effluent } \\
\text { concentration }(\mathrm{mg} / \mathrm{L})\end{array}$ & $\begin{array}{c}\mathrm{SO}_{4}{ }^{2-} \text { concentration } \\
(\mathrm{g} / \mathrm{L})\end{array}$ & $\mathrm{pH}$ & $\begin{array}{l}\text { Conductivity } \\
(\mathrm{mS} / \mathrm{cm})\end{array}$ \\
\hline $\mathrm{Fe}(\mathrm{II})$ & $990.45 \pm 10.58$ & \multirow{7}{*}{$5.17 \pm 1.02$} & \multirow{7}{*}{$1.51 \pm 0.01$} & \multirow{7}{*}{$33.7 \pm 1.0$} \\
\hline $\mathrm{Ca}$ (II) & $141.15 \pm 3.22$ & & & \\
\hline $\mathrm{Al}$ (III) & $714.58 \pm 18.53$ & & & \\
\hline $\mathrm{Cu}$ (II) & $102.22 \pm 0.43$ & & & \\
\hline $\mathrm{Mg}$ (II) & $595.61 \pm 11.50$ & & & \\
\hline $\mathrm{Ni}$ (II) & $201.50 \pm 3.29$ & & & \\
\hline $\mathrm{Mn}$ (II) & $19.99 \pm 1.95$ & & & \\
\hline
\end{tabular}

\subsection{Solvent extraction procedure}

The SX experiment was performed in $100-\mathrm{mL}$ reactors under constant agitation (400 rpm) and temperature $\left(28{ }^{\circ} \mathrm{C}\right)$. The systems were assembled from different ratios between the aqueous and organic phases $(\mathrm{A} / \mathrm{O})(0.5,1.0$ and 2.0) under a contact time of 15 minutes, enough 


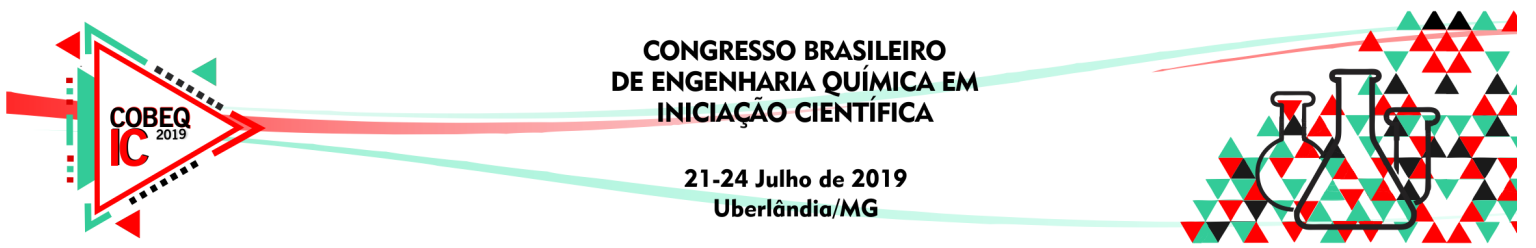

time for the dynamic equilibrium to be achieved. The system was then transferred to a $125-\mathrm{mL}$ separatory funnel, remaining at rest for 5 minutes for the aqueous and organic phase separation. The metals concentration present in the refining (aqueous phase) was determined by an atomic absorption spectrophotometer (Shimadzu AA-7000) with the aid of an external calibration curve $\left(R^{2}>0.99\right)$. The metals concentration in the organic phase was determined by mass balance. The experiments were performed in triplicate, and no organic and aqueous phases variation were observed, keeping the $\mathrm{A} / \mathrm{O}$ ration constant.

To quantify the SX process some relationships can be made. One of them is the distribution coefficient $D$ (Equation 2), and the other the separation factor $\beta$ (Equation 3). The first parameter provides information about the ion distribution between the organic and aqueous phase while the second is related to the extraction selectivity of a given ion in relation to another. Where

$$
\begin{aligned}
& D_{i}=[\mathrm{A}]_{o} /[\mathrm{A}]_{a} \\
& \beta_{i / M e}=D_{i} / D_{M e}
\end{aligned}
$$

Where $[\mathrm{A}]_{o}(\mathrm{mg} / \mathrm{L})$ and $[\mathrm{A}]_{a}(\mathrm{mg} / \mathrm{L})$ refers to the metal ion concentration in the organic and aqueous phase, respectively, when the system achieved dynamic equilibrium, $D_{i}$ and $D_{M e}$ to the distribution coefficients of the metal $i$ and related metal $(M e)$.

\section{RESULTS AND DISCUSSION}

The concentrations of each metal in the organic phase obtained in the extraction tests with Cyanex 272 as a function of the A/O ratio employed are shown in Table 1.

Table 1 - Metals concentration in the organic phase after extraction with Cyanex 272

\begin{tabular}{|c|c|c|c|}
\cline { 2 - 4 } \multicolumn{1}{c|}{} & \multicolumn{3}{|c|}{ Organic phase } \\
\cline { 2 - 4 } Metal & $\mathbf{1 : 2}$ & $\mathbf{1 : 1}$ & $\mathbf{2 : 1}$ \\
\hline $\mathrm{Fe}(\mathrm{II})$ & 382.47 & 63.72 & 78.41 \\
\hline $\mathrm{Ca}$ (II) & 20.84 & 14.42 & 35.33 \\
\hline $\mathrm{Cu}$ (II) & 30.75 & 6.14 & 20.34 \\
\hline $\mathrm{Mg}$ (II) & 44.39 & 48.71 & 106.51 \\
\hline $\mathrm{Ni}(\mathrm{II})$ & 41.43 & 25.02 & 5.33 \\
\hline $\mathrm{Mn}(\mathrm{II})$ & 6.90 & 20.01 & 48.03 \\
\hline $\mathrm{Al}(\mathrm{III})$ & 87.25 & 38.76 & 98.99 \\
\hline
\end{tabular}

It can be observed in Table 1 that the highest concentration in the organic phase was iron, due to the higher driving force for the extraction - since the highest concentration in the effluent was Fe (II). Moreover, studies have reported that Cyanex 272 has a higher distribution coefficient for this element in the $\mathrm{pH}$ range of the effluent $(\mathrm{pH} \sim 2)$ (Aliprandini, 2016). As a result of this higher extraction, the iron distribution coefficient is one of the largest in the operating conditions used in this study (Table 2). 


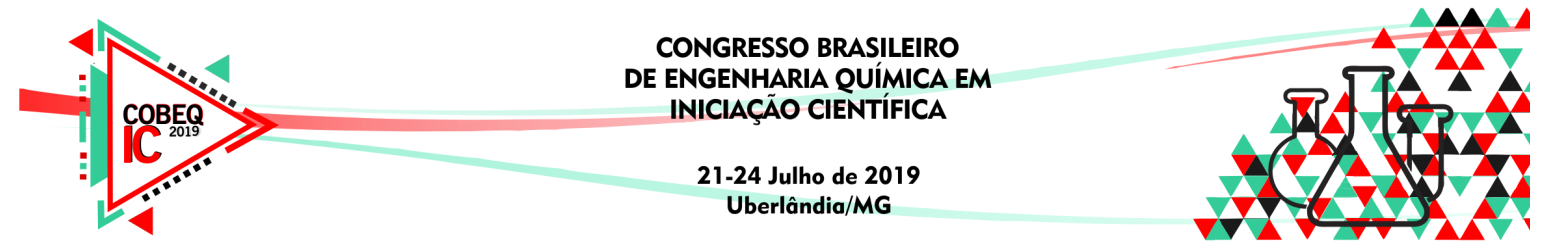

Table 2 - Distribution coefficient $(D)$ of the metals in the organic phase after solvent extraction in the respective $\mathrm{A} / \mathrm{O}$ values

\begin{tabular}{|c|c|c|c|}
\hline \multirow{2}{*}{ Metal } & \multicolumn{3}{|c|}{ Distribution coefficient } \\
\cline { 2 - 4 } & $\mathbf{1 : 2}$ & $\mathbf{1 : 1}$ & $\mathbf{2 : 1}$ \\
\hline \hline $\mathrm{Fe}(\mathrm{II})$ & 0.629 & 0.069 & 0.086 \\
\hline $\mathrm{Ca}$ (II) & 0.173 & 0.114 & 0.334 \\
\hline $\mathrm{Cu}$ (II) & 0.430 & 0.064 & 0.248 \\
\hline $\mathrm{Mg}$ (II) & 0.079 & 0.087 & 0.213 \\
\hline $\mathrm{Ni}$ (II) & 0.259 & 0.142 & 0.027 \\
\hline $\mathrm{Mn}$ (II) & 0.127 & 0.485 & 3.631 \\
\hline $\mathrm{Al}$ (III) & 0.566 & 0.191 & 0.695 \\
\hline
\end{tabular}

Figure 1 shows the removal efficiencies for all metals in distinct $\mathrm{A} / \mathrm{O}$ ratios. It can be observed that the highest average removal was for manganese $(40.8 \%)$, followed by aluminum $(31.1 \%)$, and copper $(18.7 \%)$.

Figure 1 - Removal efficiency for all metals studied in three $\mathrm{A} / \mathrm{O}$ ratios $(\mathrm{n}=3$, temperature $=$ $28^{\circ} \mathrm{C}$, contact time $=15 \mathrm{~min}$ )

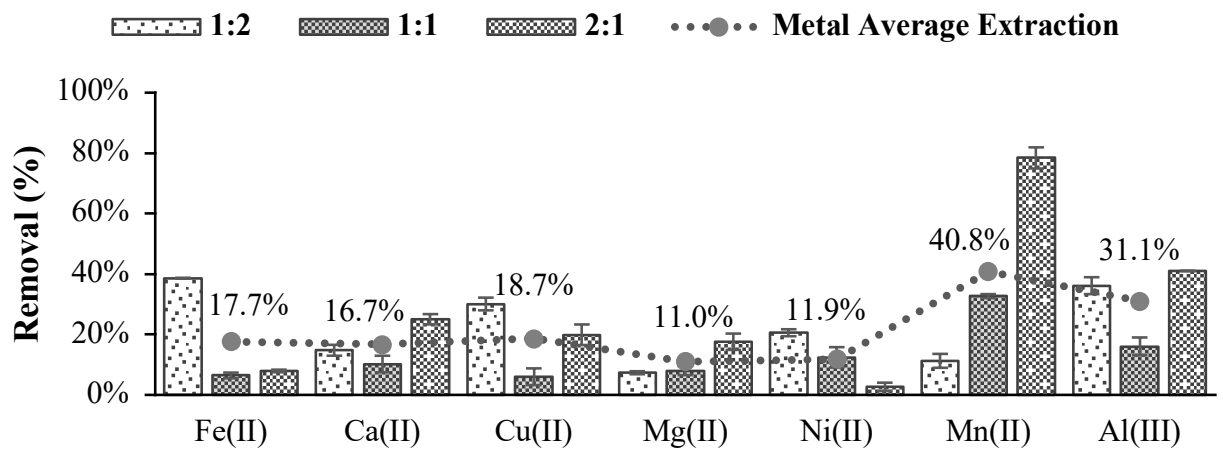

Iron is a metal with lower added value in relation to others present in this effluent. Therefore, a high separation factor $(\mathrm{Me} / \mathrm{Fe})$ is desirable. Separation factor values are given in Table 3.

Table 3 - Separation factors Me/Fe in the extraction tests with Cyanex 272

\begin{tabular}{|c|c|c|c|}
\hline \multirow{2}{*}{ Metal } & \multicolumn{3}{|c|}{ Separation factor (Me/Fe) } \\
\cline { 2 - 4 } & $\mathbf{1 : 2}$ & $\mathbf{1 : 1}$ & $\mathbf{2 : 1}$ \\
\hline \hline $\mathrm{Fe}(\mathrm{II})$ & 1.000 & 1.000 & 1.000 \\
\hline $\mathrm{Ca}$ (II) & 0.275 & 1.655 & 3.883 \\
\hline $\mathrm{Cu}$ (II) & 0.684 & 0.929 & 2.890 \\
\hline $\mathrm{Mg}$ (II) & 0.126 & 1.272 & 2.482 \\
\hline $\mathrm{Ni}$ (II) & 0.411 & 2.062 & 0.316 \\
\hline $\mathrm{Mn}$ (II) & 0.202 & 7.057 & 42.226 \\
\hline $\mathrm{Al}$ (III) & 0.900 & 2.781 & 8.083 \\
\hline
\end{tabular}

It can be seen that the separation factors obtained for $\mathrm{A} / \mathrm{O}$ of $1 / 2$ are undesirable since they are less than 1 . It is only in the $1 / 1$ and $2 / 1$ ratio that this extraction starts to be desirable, 


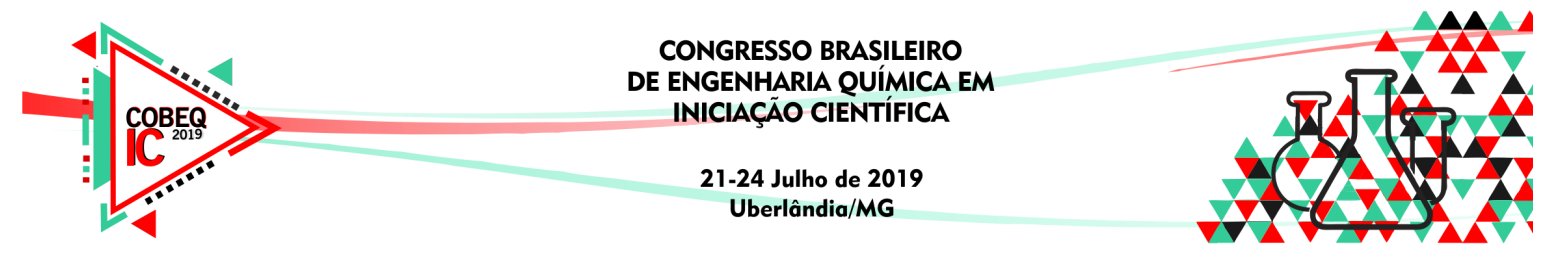

since the separation factors are greater than 1 . The highest selectivity was obtained for the $2 / 1$ ratio, being the manganese the metal that presented greater selectivity against iron.

\section{CONCLUSIONS}

The pressure oxidation process used in the gold mining beneficiation is responsible for the generation of an acid wastewater, in addition to several metals' ions. As an alternative to the conventional neutralization treatment, the solvent extraction process was evaluated in order to reduce the metallic ions concentration, besides the recovery of those that present a certain added value. Among the evaluated metals, iron was present in higher concentrations in the organic phase, justified by the greater driving force involved in its extraction process. Regarding the other metals, manganese had a higher distribution coefficient (3.631) and separation factor (42.226) in relation to iron when considering an $\mathrm{A} / \mathrm{O}$ ration of $2 / 1$, therefore, allowing the selective extraction of this compound in relation to iron.

\section{REFERENCES}

ALIPRANDINI, Paula. O uso da extração por solventes para tratamento de licor de lixiviação de minério limonítico de níquel. 2016. Dissertação (Mestrado em Engenharia Química) Escola Politécnica, Universidade de São Paulo, São Paulo, 2016. doi:10.11606/D.3.2017.tde-23022017-110109.

AMARAL, M. C. S.; GROSSI, L. B.; RAMOS, R. L.; RICCI, B. C.; ANDRADE, L. H. Integrated UF-NF-RO route for gold mining effluent treatment: From bench-scale to pilot-scale. Desalination, v. 440, p. 111-121, 2018.

REIS, B. G.; ARAÚJO, A.L. B.; AMARAL, M. C. S.; FERRAZ, H. C. Comparison of nanofiltration and direct contact membrane distillation as an alternative for gold mining effluent reclamation. Chemical Engineering and Processing - Process Intensification, v. 133, p. 24-33, 2018.

World Gold Council. Gold Demand Trends Q1 2012. Available at: https://www.gold.org/goldhub/research/gold-demand-trends/gold-demand-trends-q12012.

BANDA, Raju; JEON, Ho Seok; LEE, Man Seung. Solvent extraction separation of La from chloride solution containing Pr and Nd with Cyanex 272. Hydrometallurgy, v. 121, p. 74$80,2012$. 